\title{
Una mirada a la ley de transparencia en Chile: aspectos que condicionan su logro en lo municipal
}

A look at the transparency law in Chile: aspects the influenced its achievement at municipal level ${ }^{1}$

\section{RESUMEN}

El presente trabajo busca describir el nivel de cumplimiento de la Ley de Transparencia y Acceso a la Información Pública (TA) en el ámbito local de la Región de La Araucanía (Chile) a cinco años de haber entrado en vigencia. Esta ley establece los lineamientos para tener acceso a los procedimientos, contenidos y decisiones de la función pública a través de lo que se denomina transparencia activa. Respecto de los órganos del gobierno central, gobiernos regionales y universidades ha habido un substancial avance en la TA. Sin embargo los resultados a nivel local, apuntan al capital humano y a los procesos vinculados con la TA como las variables que más afectan en su cumplimiento.

1 El articulo es producto del proyecto de investigacion "La Ley en la Transparencia de Chile - Marco municipal", el cual esta financiado por la Universidad de la Frontera, Temuco, Chile.

2 Doctor en ciencias sociales - Facultad Latinoamericana de ciencias sociales, Sede México. A la Fecha es Docente de la Universidad Católica de Temuco, Temuco - Chile. Correo Electrónico: marco.bustos@uct.cl

3 Doctora de Investigación en ciencias sociales, Facultad Latinoamericana de ciencias sociales, Sede México. A la fecha es Docente de la Universidad de la Frontera, Temuco - Chile. Correo Electrónico: marjorie.morales@ ufrontera.cl 
Palabras clave: transparencia, información pública, gobierno local.

\begin{abstract}
This paper seeks to describe the level of compliance with the Law on Transparency and Access to Public Information (TA) at the local level in the Region of La Araucanía (Chile) five years after the entry into force. TA establishes the guidelines for the procedures to access, content and decisions of the civil service through what is called, active transparency. Regarding the organs of the central government, regional governments and universities has been a substantial progress in the TA. However the results at municipal level, indicate that human capital and the process management are the variables that affect the performance of TA.
\end{abstract}

Keywords: Transparency, public information, local government.

\title{
INTRODUCCIÓN
}

Una forma de incrementar la confianza de las personas sobre el ámbito público, es la apertura de éste a la ciudadanía: la transparencia del sector público favorece el proceso democrático, pues somete al poder, a la crítica, al control y a la vigilancia social; de manera tal que se reducen las asimetrías de poder y los costos sociales que ello implica (Mirosevic, 2011; OCDE, 2006). Sin embargo y como señala Cunill (2006), hay que considerar que la no existencia de canales adecuados de participación invalida a la transparencia como elemento que propicia la presión social y el apropiado desempeño de la administración pública. ¿Qué requisitos debe contener la información del sector público para que sea útil a la ciudadanía? Al menos, debe ser relevante, confiable, de calidad y accesible. Este último aspecto a nuestro parecer, es uno de los más importantes, pues la presencia de una normativa que regule lo que habrá de conocerse como información pública garantiza la existencia de ciertos mecanismos mínimos necesarios (canales) por las que podrá fluir la información del sector público a las personas (Cunill, 2006). 
De acuerdo con la naturaleza del problema y los objetivos, se pretende abordar el tema a partir de una investigación de tipo documental que parte de un diseño metodológico no experimental y constituye una investigación descriptiva, toda vez que se pretende caracterizar la realidad jurídica de la Ciudadanía universal y los detalles de su primer ejercicio de consagración constitucional. El estudio es cualitativo, pues se funda sobre el análisis de fuentes documentales y centra su atención, fundamentalmente, en el estado actual de la discusión jurídica y política.

Para dar cuenta de lo antes expuesto, el presente artículo se organiza en cuatro secciones; la primera, plantea el contexto por el cual surge la Ley de Transparencia y Acceso a la Información Pública en Chile; la segunda, examina el nivel de cumplimiento de la transparencia activa en la Región de La Araucanía; en la tercera sección, las consideraciones finales.

\section{Transparencia Y aCCESo a la INFORMaCión EN ChILE}

Básicamente el derecho a la información pública en Chile tiene como antecedentes legales el Artículo $8^{\circ}$ de la Constitución Política y las leyes 18.575 (sobre Bases Generales de la Administración del Estado), 19.653 (Ley de Probidad) y 19.880 (Bases de los procedimientos administrativos que rigen los actos de los Órganos de la Administración del Estado $)^{4}$. Desde lo normativo, estas leyes manifestaban la obligación de los órganos de la administración del Estado de ejercer con transparencia los actos, procesos y decisiones que le atańeran así como promocionar en forma amplia el conocimiento de los mismos.

El conjunto de normas antes indicadas consideraban como público, los actos y resoluciones de los órganos del Estado, sus fundamentos y todos los procedimientos requeridos en el adecuado desempeño de sus funciones. Ello implicaba que la función pública tiene que ejercerse con transparencia, debiendo ser públicos todos los actos administrativos del Estado así como todos los documentos que le daban sustento.

4 Biblioteca del Congreso Nacional de Chile en http://www.leychile.cl/Consulta/homebasico. 
Inclusive dichas leyes consideraban como público, la información generada por y de las empresas privadas que prestaban servicio al sector público.

Sin embargo y a pesar de que se estipulaba la capacidad de las personas a consultar los actos y documentos de los distintos órganos del Estado, en la práctica, esto no se realizaba. De las múltiples razones ${ }^{5}$, una que emanó de la legalidad fue el Decreto Supremo No 26 de 2001 (Reglamento sobre el secreto o reserva de los actos y documentos de la Administración del Estado), el cual regulaba y sancionaba la calidad de los documentos que habrían de ser públicos así como aquellos que podrían ser reservados o secretos. Muchas de las instituciones públicas se ampararon en este decreto señalando como vital y secreta muchas de las acciones que realizaban así como la documentación que generaban (BCN, 2008). Ante esta situación, en enero de 2005, los senadores Jaime Gazmuri Mujica y Hernán Larraín Fernández, presentaron la iniciativa para lo que hacia finales de 2008 y tras muchas discusiones se constituiría en la Ley 20.285 (Ley de Transparencia de la Función Pública y de Acceso a la Información de la Administración del Estado).

La Ley 20.285, entró en efecto a partir de 2009. Esta ley, regula el principio de transparencia de la función pública en Chile, garantizando el acceso a la información a los distintos órganos que conforman el sector público (ministerios o secretarías, intendencias, gobernaciones, gobiernos regionales, municipalidades, fuerzas armadas, de orden y seguridad pública y, servicios públicos). El principio de transparencia, contenido en su artículo $3^{\circ}$, consiste en respetar y cautelar la publicidad de los actos, resoluciones, procedimientos y documentos de la Administración y en facilitar el acceso de cualquier persona a dicha información.

En su artículo $5^{\circ}$, señala que la información considerada como pública, será aquella originada a partir de la utilización de los recursos públicos así como toda información que obre de poder de los órganos de la Administración, cualquiera que sea su formato, soporte, fecha de creación, origen, clasificación o procesamiento. Dentro de la información que se considera como pública, están los actos y documentos publicados

5 No existencia de bases de datos, funcionarios no capacitados, personal insuficiente, etc.

6 Actualmente derogado. 
en el Diario Oficial así como aquellos que tengan relación con las funciones, competencias y responsabilidades de los órganos de la Administración del Estado (artículo $6^{\circ}$, Ley 20.285). Siendo la transparencia un aspecto tan sensible de ser manipulado, dentro de la Ley de Transparencia se señala la creación de un Consejo como ente promotor y fiscalizador con facultades para sancionar el incumplimiento del mismo (artículo 31).

Un cambio importante que implicó la transparencia en Chile, fue la incorporación de las tecnologías de información así como un conjunto de elementos mínimos sobre el quehacer público a libre disposición de las personas físicas o jurídicas. La Ley 20.285 señala en su artículo $7^{\circ}$, que los órganos de la Administración del Estado, deben mantener en forma actualizada y a disposición permanente del público en sitios electrónicos al menos los siguientes elementos:

- Estructura orgánica, funciones, facultades y atribuciones

- Marco normativo

- Contrataciones de bienes y servicios

- Transferencias

- Actos y resoluciones

- Normativa para acceder a los servicios y programas del respectivo órgano público

- Mecanismos de participación ciudadana

- Ley de presupuesto y ejercicio del presupuesto

- Auditorias

De igual forma, entre los cambios significativos que trajo la Ley 20.285 está el tiempo de respuesta a las solicitudes de información que no forman parte de la transparencia activa (toda solicitud de información debe ser atendida en un plazo no mayor a veinte días, prorrogables hasta por diez más si lo amerita la situación), la relevancia de los intereses de los solicitantes (la información debe ser entregada en la forma y medio requerida por el solicitante) y el principio de gratuidad (si bien existe un principio de gratuidad en la divulgación de la información pública, los órganos están facultados para exigir eventualmente un pago por la reproducción y envío de la información, tal como ocurre en el contexto mexicano). Por otro 
lado, deja en claro los límites en el acceso a la información, esto es, cuando exista o pueda existir la afectación de terceros, de los funcionarios públicos, de los órganos de la administración pública y del ejercicio de sus funciones así como la seguridad nacional, política exterior o integridad territorial (modificando así la discrecionalidad que otorgaba del Decreto Supremo $\mathrm{N}^{\circ}$ 26). Así como las acciones que habrán de seguir los solicitantes de información en el caso de que hubiese expirado el plazo para la entrega de información solicitada o ésta fuere denegada (la interpelación ante el Consejo para la Transparencia y la Corte de Apelaciones como última instancia). Otro de los cambios significativos, fue la celeridad del cumplimiento de la Ley o la actitud de los funcionarios ante ésta por la serie de sanciones a las que se pueden hacer merecedores: la negación injustificada de información, la entrega no oportuna y el incumplimiento de las normas de transparencia activa serán sancionadas con una multa que va del 20 al $50 \%$ de la remuneración del infractor (en el caso de que éste mantuviese la misma actitud se duplicará la multa y será suspendido del ejercicio de su cargo por cinco días). Las sanciones correspondientes serán dictadas por el Consejo para la Transparencia o por la Corte de Apelaciones, según fuera el caso.

Entre los órganos del Estado que han puesto a disposición en su respectiva página web la información que obliga la ley (y sobre algunas de las cuales se mantenía el secreto absoluto) tenemos a las Empresas Públicas (ej. Corporación Nacional del Cobre de Chile, Banco del Estado de Chile, Metro), Fundaciones (ej. Fundación Artesanías de Chile, Fundación Integra), Organismos Autónomos (ej. Controlaría General de la República, Instituto Nacional de Derechos Humanos), Universidades públicas (ej. Universidad de La Frontera, Universidad de La Frontera, Universidad Tecnológica Metropolitana), Presidencia de la República, Ministerios y Subsecretarías (ej. Ministerio de la Defensa, Ministerio de Educación, Ministerio de Hacienda, Banco Central), Gobiernos Regionales y Municipalidades. Asimismo, en casi todos estos órganos encontramos un hipervínculo hacia el formato o formulario que se requiere para la transparencia pasiva (aquella información que no contempla su disposición obligatoria pero que forma parte del quehacer público).

Para apoyar y estandarizar el cumplimiento de la TA, el Consejo para la Transparencia ha publicado en su página web los formatos que deben considerar los órganos del Estado respecto de la información a disposición obligada. Para dar cuenta de su 
nivel de cumplimiento, el Consejo para la Transparencia revisa la información que se encuentra disponible al público en los respectivos sitios generando para cada uno su respectivo informe. En el caso de las instituciones del Gobierno Central estas auditorías se practican desde 2010 en forma sistemática, a las Universidades desde 2011 y a las municipalidades desde $2012^{7}$ (a las empresas públicas se practicó por primera vez en 2014).

En la Tabla 1, se aprecia el nivel de cumplimiento promedio alcanzado respecto de la TA. Los órganos del Gobierno Central (incluye gobiernos regionales y provinciales), son las instancias públicas con mayor logro en cuanto a TA se refiere. Al observar los resultados de las municipalidades encontramos que en promedio es bajo el nivel de cumplimiento alcanzado, llamando la atención por el tiempo en vigencia de la Ley 20.285. El nivel de cumplimiento de las municipalidades cobra importancia si consideramos que son la primera imagen que tienen los ciudadanos respecto del gobierno y se vuelve aún más importante si consideramos el nivel de participación que se quiere gestar en la ciudadanía vinculada a los procesos decisorios ${ }^{8}$. Tratando de dar cuenta de los factores que inciden en esta situación, en el apartado siguiente se presenta el caso de las municipalidades de la Región de La Araucanía.

Tabla 1. Nivel de cumplimiento de la TA en Chile.

\begin{tabular}{|c|c|c|c|c|}
\hline Órgano & 2010 & 2011 & 2012 & 2013 \\
\hline Gobierno central & 93,8 & 95,2 & 96,9 & 96,3 \\
\hline Universidades & & 20,5 & 77,9 & 90,5 \\
\hline Municipalidades & & & 30,3 & 47,4 \\
\hline
\end{tabular}

Fuente: elaboración propia con información del Consejo para la Transparencia.

7 Todavía no están disponibles los informes correspondientes a 2014.

8 Como apunta la Ley 20.500 Sobre asociaciones y participación ciudadana en la gestión pública. 


\section{NiVEL DE CUMPLIMIENTO EN LA IX REGIÓN}

La Región de La Araucanía, se localiza al sur de Chile. Está conformada por 32 municipalidades, las cuales se agrupan en dos provincias: Malleco y Cautín. El número de habitantes proyectados para el año 2013 fue de $994.380^{\circ}$, de los cuales el $51 \%$ correspondería al género femenino. De acuerdo al Gobierno de Chile (2010), la región presenta un atraso de veinte años con el resto del país, en lo económico, social y educacional: El PIB e ingreso per cápita de la región es el más bajo de Chile; el porcentaje de indigencia, desempleo y analfabetismo corresponden a los más altos del país. Respecto de los niveles de educación, el $47 \%$, cuenta con educación básica; el $31 \%$ cuenta con educación media, el $4 \%$ ha realizado estudios técnicos o en institutos y, sólo el $8 \%$ cuenta con educación superior ${ }^{10}$. Si a lo anterior sumamos el conflicto indígena (lucha por reconocimiento y autonomía), el escenario se hace más complejo.

Las municipalidades en Chile, se rigen por la Ley 18.695 (Orgánica Constitucional de Municipalidades). En su artículo $12^{\circ}$, se señala que las ordenanzas, resoluciones, reglamentos, decretos estarán a disposición del público y deberán ser publicadas en los sistemas electrónicos o digitales de que disponga la municipalidad (esta disposición se incorporó a partir de la promulgación de la Ley 20.285). Para que la ciudadanía encuentre una contraparte en los gobiernos locales que atienda a sus demandas en el artículo $98^{\circ}$ de la Ley Orgánica Constitucional de Municipalidades, se establece la conformación de la oficina de informaciones, reclamos y sugerencias (OIRS) así como la información que estará a disposición del público en forma permanente:

- El plan comunal de desarrollo, el presupuesto municipal y el plan regulador comunal

- Los convenios, contratos y concesiones

- Las cuentas públicas de los alcaldes

- Los registros mensuales de gastos efectuados

9 INE (2014). Proyecciones de Población, total por años, región, provicia y comunas en http://www.inearaucania.cl/ contenido.aspx?id_contenido $=13$

10 INE (2014). Censo 2002, en http://www.inearaucania.cl/contenido.aspx?id_contenido=13 
- El reglamento interno, el reglamento de contrataciones y adquisiciones, la ordenanza de participación y todas las ordenanzas y resoluciones municipales

Aspectos que se suman a lo estipulado por la TA. De acuerdo a lo establecido por la Ley 20.285 y a las modificaciones incorporadas a la Ley 18.695, las municipalidades deben incorporar un su sitio web un banner de trasparencia activa donde se presenten en forma actualizada los aspectos antes señalados. Para observar el nivel de cumplimiento a nivel municipal, el Consejo para la Transparencia ha establecido un instrumento $^{11}$ que consta de 242 preguntas, dividida en ocho apartados, cada con sus respectivos ítems y subítems. Cada uno de los ítems y subítems, se le asigna una ponderación cuyo valor máximo total alcanzable es $100 \%$ (ver tabla 2). En el caso de los subítems, los aspectos que superan las facultades de las municipalidades no son consideradas en el cálculo del nivel de cumplimiento, ajustándose el cálculo del nivel de cumplimiento.

De acuerdo a los informes de fiscalización (Consejo para la Transparencia, 2013), el nivel de cumplimiento de la Transparencia Activa Municipal (TAM) a nivel nacional en 2012 y en 2013 fue de $30.3 \%$ y $47.4 \%$, respectivamente. En el caso de la Región de La Araucanía, el nivel de cumplimiento de la TAM fue de $22.62 \%$ y $50.23 \%$ respectivamente para los mismos años. En la Figura 1, se presenta el nivel de cumplimiento alcanzado en la Región de La Araucanía en el periodo 2012-2013. Quedan fuera del análisis las municipalidades de Ercilla y Puerto Saavedra por no contar con información en alguno de los dos años considerados.

De acuerdo a la información presentada por el Consejo para la Transparencia, en 2012, diez municipalidades superaron el promedio regional y de estas sólo seis se encontraron por encima del promedio nacional. En 2013, hay un cambio en esta situación, siendo catorce las municipalidades que superaron tanto el promedio regional como el nacional. Hay que mencionar que Angol, Cholchol, Collipulli, Gorbea, Loncoche, Padre Las Casas, Pitrufquén y Toltén, experimentaron una mejoría substancial en su nivel de cumplimiento de al menos un $39 \%$ de un año a otro.

11 Este instrumento es muy similar al que se aplica a los otros órganos del Gobierno en cuanto a apartados y ponderaciones se refiere. La diferencia estriba en que estos instrumentos consideran 252 preguntas. 
Tabla 2. Apartados, ponderaciones e ítems.

\begin{tabular}{|c|c|c|c|}
\hline Apartado & Ponderación & & Items de Instructivo \\
\hline $\begin{array}{l}\text { Aspectos } \\
\text { Generales }\end{array}$ & $10 \%$ & G & General \\
\hline \multirow{2}{*}{$\begin{array}{l}\text { Actos y decisiones } \\
\text { del organismo }\end{array}$} & \multirow{2}{*}{$10 \%$} & 1.1 & Actos y documentos del organismo \\
\hline & & 1.7 & $\begin{array}{l}\text { Los actos y resoluciones que tengan efectos sobre } \\
\text { terceros }\end{array}$ \\
\hline \multirow{3}{*}{$\begin{array}{l}\text { Organización } \\
\text { interna }\end{array}$} & \multirow{3}{*}{$15 \%$} & 1.2 & $\begin{array}{l}\text { Potestades, competencias, responsabilidades, } \\
\text { funciones, atribuciones y/o tareas y Marco } \\
\text { Normativo }\end{array}$ \\
\hline & & 1.3 & $\begin{array}{l}\text { La estructura orgánica del órgano y las facultades, } \\
\text { funciones y atribuciones de cada una de las } \\
\text { unidades u órganos internos. }\end{array}$ \\
\hline & & 1.13 & $\begin{array}{l}\text { Todas las Entidades en que tengan participación, } \\
\text { representación e intervención, cualquiera sea su } \\
\text { naturaleza y el fundamento normativo que la } \\
\text { justifica. }\end{array}$ \\
\hline $\begin{array}{l}\text { Personal y } \\
\text { Remuneraciones }\end{array}$ & $10 \%$ & 1.4 & $\begin{array}{l}\text { El personal de planta, a contratar y el que se } \\
\text { desempeñe en virtud de un contrato de trabajo, y } \\
\text { las personas naturales contratadas a honorarios, con } \\
\text { las correspondientes remuneraciones. }\end{array}$ \\
\hline
\end{tabular}

Las contrataciones para el suministro de bienes muebles, para la prestación de servicios, para la ejecución de acciones de apoyo y para la ejecución

Compras y

Licitaciones

$8 \%$ de obras, y las contrataciones de estudios, asesorías

1.5 y consultorías relacionadas con proyectos de inversión, con indicaciones de los contratistas e identificación de los socios y accionistas principales de las sociedades o empresas prestadoras, o en su caso. 


\begin{tabular}{|c|c|c|c|}
\hline Apartado & Ponderación & & Items de Instructivo \\
\hline \multirow[t]{2}{*}{$\begin{array}{l}\text { Subsidios y } \\
\text { Transferencia }\end{array}$} & \multirow[t]{2}{*}{$20 \%$} & 1.6 & $\begin{array}{l}\text { Las transferencias de fondos públicos que efectúen, } \\
\text { incluyendo todo aporte económico entregado } \\
\text { a personas jurídicas o naturales, directamente o } \\
\text { mediante procedimientos concursales, sin que éstas } \\
\text { o aquellas realicen una contraprestación reciproca } \\
\text { en bienes o servicios. }\end{array}$ \\
\hline & & 1.9 & $\begin{array}{l}\text { El diseño, montos asignados y criterios de acceso } \\
\text { a los programas de subsidios y otros beneficios } \\
\text { que entregue el respectivo órgano, además de las } \\
\text { nóminas de beneficiarios de los programas sociales } \\
\text { en ejecución. }\end{array}$ \\
\hline \multirow{2}{*}{$\begin{array}{l}\text { Presupuesto y } \\
\text { auditoría }\end{array}$} & \multirow[b]{2}{*}{$20 \%$} & 1.11 & Información Presupuestaria \\
\hline & & 1.12 & $\begin{array}{l}\text { Los resultados de las auditorías al ejercicio } \\
\text { presupuestario del respectivo órgano y, en su caso, } \\
\text { las aclaraciones que procedan }\end{array}$ \\
\hline \multirow[t]{2}{*}{$\begin{array}{l}\text { Relacion con la } \\
\text { Ciudadanía }\end{array}$} & \multirow[t]{2}{*}{$7 \%$} & 1.8 & $\begin{array}{l}\text { Los trámites y requisitos que debe cumplir el } \\
\text { interesado para tener acceso a los servicios que } \\
\text { preste el respectivo órgano. }\end{array}$ \\
\hline & & 1.10 & Los mecanismos de participación ciudadana \\
\hline
\end{tabular}

Fuente: Consejo para la Transparencia.

De las dieciséis municipalidades por debajo del promedio regional y nacional en 2013, siete (Carahue, Cunco, Curacautín, Currarrehue, Lonquimay, Lumaco y Teodoro Schmidt) presentan una situación alarmante pues el nivel de cumplimiento se encuentra por debajo o muy cercano al nivel de cumplimiento de 2012. Por otro lado, hay siete municipalidades se encuentran en los dos años por encima del nivel promedio de cumplimiento de TAM (Gorbea, Loncoche, Padre las Casas, Pitrufqén, Reinaco, Temuco y Victoria). De éstas, destaca el alto grado de cumplimiento en 2013 de Loncoche, Padre Las Casas y Victoria, muy cercano al valor máximo que se 
puede obtener $(91.6 \%, 96.3 \%, 91.9 \% \text {, respectivamente })^{12}$. En las tablas 3 y 4 , se pueden apreciar el nivel de cumplimiento en 2013 de las siete municipalidades con las calificaciones más bajas y más altas.

Figura 1. La Araucanía: nivel de cumplimiento de TA, 2012-2013.

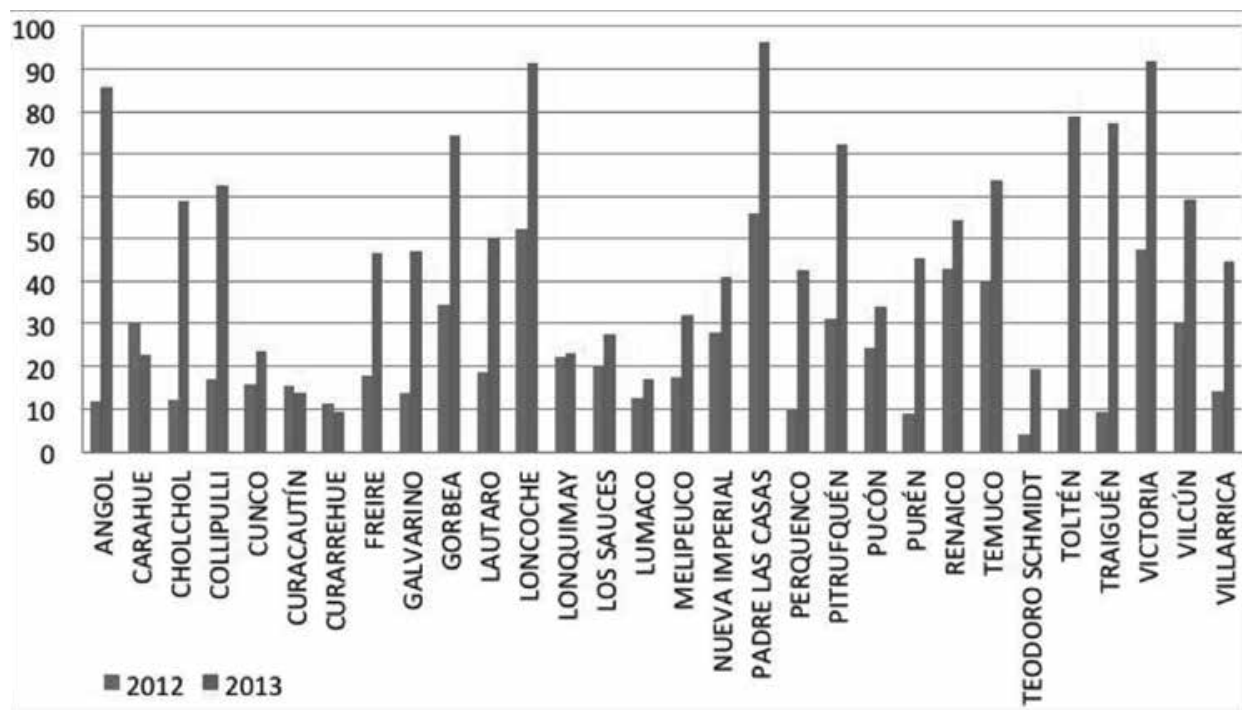

Nota: Considera solo las municipalidades con información en el periodo considerado.

Fuente: elaboración propia.

Tabla 3. Nivel de cumplimiento por ítem de las municipalidades con peor calificación.

\begin{tabular}{|lccccccc|} 
Municipalidad & carahue & cunco & curacautín & curarrehue & lonquimay & lumaco & $\begin{array}{c}\text { teodoro } \\
\text { schmidt }\end{array}$ \\
\hline $\begin{array}{l}\text { Aspectos } \\
\text { generales }\end{array}$ & 9,29 & 9,29 & 3,57 & 3,57 & 10,00 & 3,57 & 4,29 \\
$\begin{array}{l}\text { Actas y } \\
\text { decisiones }\end{array}$ & 0,00 & 7,31 & 5,00 & 0,00 & 2,14 & 0,00 & 2,86 \\
\hline
\end{tabular}

12 Similar o mayor al nivel de cumplimiento de municipalidades localizadas en la Región Metropolitana. 


\begin{tabular}{|lccccccc|}
\hline Municipalidad & carahue & cunco & curacautín & curarrehue & lonquimay & lumaco & $\begin{array}{c}\text { teodoro } \\
\text { schmidt }\end{array}$ \\
\hline 1.1 & 0,00 & 100,00 & 100,00 & 0,00 & 42,86 & 0,00 & 57,14 \\
\hline 1.7 & 0,00 & 46,15 & 0,00 & 0,00 & 0,00 & 0,00 & 0,00 \\
\hline $\begin{array}{l}\text { Organización } \\
\text { interna }\end{array}$ & 1,25 & 4,31 & 4,86 & 2,78 & 2,50 & 5,42 & 0,00 \\
\hline 1.2 & 0,00 & 11,11 & 72,22 & 55,56 & 50,00 & 83,33 & 0,00 \\
\hline 1.3 & 25,00 & 75,00 & 25,00 & 0,00 & 0,00 & 25,00 & 0,00 \\
\hline 1.13 & 0,00 & 0,00 & 0,00 & 0,00 & 0,00 & 0,00 & 0,00 \\
\hline $\begin{array}{l}\text { Personal y } \\
\text { remuneración }\end{array}$ & 6,98 & 0,00 & 0,16 & 0,00 & 0,00 & 1,09 & 0,00 \\
\hline 1.4 & 69,84 & 0,00 & 1,56 & 0,00 & 0,00 & 10,94 & 0,00 \\
\hline $\begin{array}{l}\text { Compras y } \\
\text { licitaciones }\end{array}$ & 0,00 & 0,41 & 0,21 & 0,41 & 0,00 & 0,21 & 0,00 \\
\hline 1.5 & 0,00 & 5,13 & 2,56 & 5,13 & 0,00 & 2,56 & 0,00 \\
\hline $\begin{array}{l}\text { Subsidios y } \\
\text { transferencias }\end{array}$ & 3,33 & 2,00 & 0,00 & 0,00 & 2,80 & 1,60 & 1,67 \\
\hline 1.6 & 0,00 & 20,00 & 0,00 & 0,00 & 0,00 & 0,00 & 0,00 \\
\hline 1.9 & 33,30 & 0,00 & 0,00 & 0,00 & 28,00 & 16,00 & 16,67 \\
\hline $\begin{array}{l}\text { Presupuesto y } \\
\text { auditorias }\end{array}$ & 1,67 & 0,00 & 0,00 & 1,67 & 5,71 & 5,00 & 10,00 \\
\hline 1.11 & 16,67 & 0,00 & 0,00 & 16,67 & 0,00 & 50,00 & 100,00 \\
\hline 1.12 & 0,00 & 0,00 & 0,00 & 0,00 & 57,14 & 0,00 & 0,00 \\
\hline $\begin{array}{l}\text { Relación con la } \\
\text { ciudadanía }\end{array}$ & 0,00 & 0,00 & 0,00 & 0,70 & 0,00 & 0,00 & 0,70 \\
\hline 1.8 & 0,00 & 0,00 & 0,00 & 0,00 & 0,00 & 0,00 & 0,00 \\
\hline 1.10 & 0,00 & 0,00 & 0,00 & 20,00 & 0,00 & 0,00 & 20,00 \\
\hline Resultado & 22,52 & 23,32 & 13,80 & 9,13 & 23,15 & 16,89 & 19,52 \\
\hline
\end{tabular}

Fuente: elaboración propia.

Como se puede apreciar en las tablas 3 y 4, no se puede identificar un patrón que explique tales resultados, respecto del logro en los distintos ítems que conforman el instrumento de evaluación. En el caso de las municipalidades con alto cumplimiento o mejora substancial, se puede deber a un adecuado manejo de la información o 
una mejora en los procesos internos que involucran la utilización de internet y la vinculación de la información digitalizada mínima que marca la ley en el portal institucional correspondiente. En el caso de las municipalidades con peor calificación, esta puede deberse a tres situaciones: tener un portal web sin haber incorporado el banner de transparencia o los ítems a ser evaluados; el incorrecto funcionamiento de los hipervínculos dentro del link de transparencia información no actualizada.

Tabla 4. Nivel de cumplimiento por ítem de las municipalidades con más alta calificación.

\begin{tabular}{lccccccc}
\hline $\begin{array}{l}\text { Municipalidad } \\
\text { gorbea }\end{array}$ & loncoche & $\begin{array}{c}\text { padre } \\
\text { las casas }\end{array}$ & pitrufquén & renaico & temuco & victoria \\
\hline $\begin{array}{l}\text { Aspectos } \\
\text { generales }\end{array}$ & 10,00 & 10,00 & 10,00 & 10,00 & 10,00 & 8,57 & 9,29 \\
\hline $\begin{array}{l}\text { Actas y } \\
\text { decisiones }\end{array}$ & 8,08 & 10,00 & 9,58 & 10,00 & 5,00 & 9,58 & 9,58 \\
\hline 1.1 & 100,00 & 10,00 & 100,00 & 100,00 & 100,00 & 100,00 & 100,00 \\
\hline 1.7 & 61,54 & 100,00 & 91,67 & 100,00 & 0,00 & 91,67 & 91,67 \\
\hline $\begin{array}{l}\text { Organización } \\
\text { interna }\end{array}$ & 15,00 & 15,00 & 14,44 & 7,32 & 5,56 & 3,35 & 13,89 \\
\hline 1.2 & 100,00 & 100,00 & 88,89 & 50,00 & 11,11 & 27,78 & 77,78 \\
\hline 1.3 & 100,00 & 100,00 & 100,00 & 25,00 & 100,00 & 25,00 & 100,00 \\
\hline 1.13 & 100,00 & 100,00 & 100,00 & 71,43 & 0,00 & 14,29 & 100,00 \\
\hline $\begin{array}{l}\text { Personal y } \\
\text { remuneración }\end{array}$ & 10,00 & 10,00 & 10,00 & 0,00 & 7,26 & 8,23 & 8,52 \\
\hline 1.4 & 100,00 & 100,00 & 100,00 & 0,00 & 72,58 & 82,26 & 85,25 \\
\hline $\begin{array}{l}\text { Compras y } \\
\text { licitaciones }\end{array}$ & 7,77 & 8,00 & 8,00 & 8,00 & 0,21 & 7,77 & 8,00 \\
\hline 1.5 & 97,14 & 100,00 & 100,00 & 100,00 & 2,56 & 97,14 & 100,00 \\
\hline $\begin{array}{l}\text { Subsidios y } \\
\text { transferencias }\end{array}$ & 13,20 & 11,60 & 20,00 & 12,17 & 8,80 & 7,67 & 18,57 \\
\hline 1.6 & 100,00 & 100,00 & 100,00 & 100,00 & 20,00 & 10,00 & 90,00 \\
\hline 1.9 & 32,00 & 16,00 & 100,00 & 21,74 & 68,00 & 66,67 & 95,65 \\
\hline
\end{tabular}


Marco Bustos Gutiérrez, Marjorie Morales Casetti

\begin{tabular}{|lccccccc|}
\hline Municipalidad & gorbea & loncoche & $\begin{array}{c}\text { padre } \\
\text { las casas }\end{array}$ & pitrufquén & renaico & temuco & victoria \\
\hline $\begin{array}{l}\text { Presupuesto y } \\
\text { auditorias }\end{array}$ & 8,57 & 20,00 & 18,33 & 20,00 & 13,33 & 12,62 & 18,57 \\
\hline 1.11 & 28,57 & 100,00 & 83,33 & 100,00 & 33,33 & 83,33 & 100,00 \\
\hline 1.12 & 57,14 & 100,00 & 100,00 & 100,00 & 100,00 & 42,86 & 85,71 \\
\hline $\begin{array}{l}\text { Relación con la } \\
\text { ciudadanía }\end{array}$ & 1,75 & 7,00 & 5,95 & 4,90 & 4,20 & 5,95 & 5,56 \\
\hline 1.8 & 50,00 & 100,00 & 100,00 & 100,00 & 100,00 & 100,00 & 88,89 \\
\hline 1.10 & 0,00 & 100,00 & 70,00 & 40,00 & 20,00 & 70,00 & 70,00 \\
\hline Resultado & 74,37 & 91,60 & 96,30 & 72,39 & 54,36 & 63,74 & 91,98 \\
\hline
\end{tabular}

Fuente: elaboración propia.

¿Qué aspectos condicionan entonces el logro de la TAM en La Araucanía? En la tabla 5 se muestran algunas de las variables socioeconómicas contenidas en el Sistema Nacional de Información Municipal de Chile ${ }^{13}$, de las municipalidades con el mayor y menor nivel de cumplimiento. En la primera columna se muestra la diferencia que tuvo cada municipalidad respecto de su respectivo nivel de cumplimiento. Destacan Carahue, Curacautín y Currarrehue con una calificación negativa. La pobreza que impera entre los habitantes del municipio no parece ser un factor decisor en el cumplimiento de la TAM, como podemos apreciar en el caso de Lumaco y Loncoche. El nivel de ruralidad y la dependencia de recursos del Fondo Común Municipal parecen ser factores que influyen en el cumplimiento de la TAM, ya que se encuentran relacionados con la capacidad técnica y el desempeño de las instituciones públicas regionales y locales. Otro factor que se considera importante para el cumplimiento es la militancia política de los alcaldes, en el caso de las municipalidades mejor evaluadas el $43 \%$ son de derecha y el $57 \%$ restante son de izquierda y regionalistas (en igual proporción). En el caso de las peor evaluadas, estás son mayoritariamente de izquierda (72\%).

13 En http://www.sinim.cl/. 
Tabla 5. Variables socioeconómicas de las municipalidades con alto y bajo nivel de cumplimiento en el periodo 2012-2013.

\begin{tabular}{|c|c|c|c|c|c|c|}
\hline Municipalidad & $\begin{array}{c}\text { Dif. } \\
\text { 2013-2012 }\end{array}$ & $\begin{array}{l}\text { Población } \\
\text { en condición } \\
\text { de Pobreza }\end{array}$ & Ruralidad & $\begin{array}{l}\text { Dependencia } \\
\text { del fcm }\end{array}$ & $\begin{array}{c}\text { Grado } \\
\text { del } \\
\text { alcalde }\end{array}$ & $\begin{array}{l}\text { Profesionalización } \\
\text { de los funcionarios }\end{array}$ \\
\hline Carahue & $-7,7$ & 32,5 & 58,1 & 88,7 & 5 & 26,3 \\
\hline Cunco & 7,7 & 27,8 & 61,6 & 78,9 & 6 & 20,5 \\
\hline Curacautín & $-1,7$ & 34,4 & 32,4 & 84,1 & 6 & 12,8 \\
\hline Curarrehue & $-2,0$ & 23,3 & 78,9 & 94,3 & 6 & 19,4 \\
\hline Lonquimay & 1,0 & 30,5 & 66,6 & 87,9 & 6 & 23,8 \\
\hline Lumaco & 4,3 & 36,8 & 60,0 & 91,3 & 6 & 29,0 \\
\hline $\begin{array}{l}\text { Teodoro } \\
\text { Schmidt }\end{array}$ & 15,7 & 29,5 & 43,7 & 88,8 & 6 & 31,0 \\
\hline Promedio & & 30,7 & 57,3 & 87,7 & & 23,2 \\
\hline Gorbea & 39,8 & 27,0 & 41,6 & 75,8 & 6 & 17,9 \\
\hline Loncoche & 39,3 & 36,5 & 36,3 & 76,9 & 5 & 24,7 \\
\hline $\begin{array}{l}\text { Padre Las } \\
\text { Casas }\end{array}$ & 40,1 & 28,4 & 49,8 & 80,0 & 4 & 34,1 \\
\hline Pitrufquén & 41,3 & 20,3 & 37,1 & 78,5 & 6 & 20,3 \\
\hline Renaico & 11,2 & 33,1 & 12,1 & 87,6 & 6 & 27,0 \\
\hline Temuco & 23,5 & 21,2 & 7,0 & 36,2 & 2 & 25,6 \\
\hline Victoria & 44,7 & 31,0 & 29,2 & 69,6 & 4 & 17,2 \\
\hline Promedio & & 28,2 & 30,5 & 72,1 & & 23,8 \\
\hline
\end{tabular}

Fuente: elaboración propia.

Sin embargo y como señalan, Bernas y Valdivieso (2014), pueden existir otros aspectos que afectan el cumplimiento de la TAM. Un elemento que siempre se señala para el cumplimiento adecuado de las actividades que se realizan en cualquier 
organización es el capital humano involucrado, puesto que son los encargados de administrar y gestionar los recursos y procesos (Ajenjo, 2005). Pero si consideramos el nivel jerárquico de los alcaldes y el nivel de profesionalización de los funcionarios municipales (funcionarios profesionales respecto del total de funcionarios), encontramos que no existe mucha diferencia entre los municipios con bajo y alto nivel de cumplimiento. Por lo que deben ser otras las condicionantes que inciden en el logro de la TAM.

\section{REFLEXIONES FinAles}

Tras cinco años de haberse promulgado la Ley de Transparencia de la Función Pública y de Acceso a la Información de la Administración del Estado, queda mucho por hacer. En el caso de los niveles más altos de gobierno el cumplimiento de la TA parece haber avanzado sustancialmente, llegando casi al $100 \%$ de los aspectos mínimos que deben ser informados a la ciudadanía en general. En el caso de las municipalidades es poco el avance que se ha tenido. Si consideramos el logro promedio nacional, en los años considerados, éste aumentó sólo en un $17 \%$. En el caso de la Región de La Araucanía, encontramos que hay un avance substancial, superando incluso el nivel de cumplimiento promedio nacional. Sin embargo este avance no es mayoritario, pues encontramos también que en algunos casos, el retroceso en el nivel de cumplimiento de la TA. Algo que parece congruente con otros estudios son las condiciones socioeconómicas imperantes de las localidades con el bajo desempeño. Condición que no se cumple cuando contemplamos en el nivel de profesionalización de las municipalidades, por lo que deben existir otros aspectos que condicionen el cumplimiento de la TAM.

A pesar de lo anterior, se observa como positiva la existencia de una ley que propicie y proteja el derecho de fiscalizar a los órganos del Estado. A este respecto, Paredes (2011) señala que se hace necesario el reconocimiento de los actores involucrados en el proceso decisorio así como el establecimiento de los elementos normativos que regulen su interacción tanto en lo político como en lo social. Esto cobra vital importancia, si consideramos que Latinoamérica se encuentra transitando hacia una crisis de confianza para con las instituciones como consecuencia de una serie de 
promesas de campañas y de gobierno no cumplidas (Bustos y Morales, 2012; Corral, 2008; Paredes, 2011; Quiroga, 2008; Segovia et al., 2008), poniendo en tela de juicio el papel de la democracia.

Entre las limitaciones de esta investigación, se encuentra el número de años considerados y la falta de un desglose de los aspectos que propician el incumplimiento de la TA así como de los efectos de incorporar en la estructura organizacional de las municipalidades las Oficinas de Información, Reclamos y Sugerencias. Queda como trabajo a seguir, profundizar en el papel que tiene el personal profesional de las municipalidades dentro de los distintos procesos que se realizan en ella así como con los vinculados directamente con los procesos relativos a la gestión de la TAM. De igual forma, se hace necesario profundizar en los aspectos tecnológicos y de infraestructura asociados a la difusión y acceso a la información tanto de las municipalidades con peor y mejor nivel de cumplimiento con el fin de compartir experiencias y buenas prácticas. Un aspecto que no está considerado en este estudio y que se vislumbra como una futura línea de investigación es el nivel de satisfacción y utilidad de los distintos usuarios de la información que ofrecen los municipios en sus respectivos portales así como de la requerida vía solicitud escrita (Transparencia Pasiva).

\section{REFERENCIAS}

Ajenjo, D. (2005). "Dirección y gestión de proyectos. Un enfoque de práctico", México: Alfaomega

Biblioteca del Congreso Nacional. (2008). "Historia de la Ley 20.285, Sobre acceso a la información pública”, [en línea] Recuperado de http://www.leychile.cl/Consulta/ portada_hl?tipo_norma=XX1\&nro_ley=20285

Bernas, J. y Patricio V., http://www.sociedadpoliticaspublicas.cl/archivos/CBLOQUET/ Panel_Patrimonio_Cultura_y_Participacion_Local/Politica\%20de\%20Transparencia\%20y\%20Participacion\%20Ciudadana\%20en\%20los\%20Municipios.pdf 
Bustos, M. y Marjorie, M. "Determinantes de la confianza institucional en Chile y en La Araucanía”, recuperado de http://gigapp.org/administrator/components/com_jresearch/ files/publications/G02-BUSTOS_GUTIERREZ-2013.pdf

Consejo para la Transparencia (2013). "Informe sobre Fiscalización Activa, Municipalidad de Angol” recuperado de http://www.cplt.cl/consejo/site/edic/base/port/fiscalizacion.html

Corral, M. (2008). "Desconfianza en los partidos políticos en América Latina”, Perspectivas desde el Barómetro de las Américas: 2008 (Num. 2), recuperado de http://www.vanderbilt. edu/lapop/insights/I0802es.pdf

Cunill, N. (2006), “La Transparencia en la Gestión Pública ¿Cómo construirle viabilidad?”, Estado, gobierno, gestión pública: Revista Chilena de Administración Pública,No 8, pp. $22-44$.

Gobierno de Chile (2012), "Plan Araucanía”, recuperado de http://araucania7.cl/wp-content/uploads/DOCUMENTO_PA7.pdf

Mirosevic, C. (2011). "La participación ciudadana en el procedimiento de evaluación de impacto ambiental y las reformas introducidas por la Ley No 20.417”, Revista de Derecho, $\mathrm{N}^{\circ} 36$, pp. 281-323.

OCDE (2006). Participación ciudadana. Manual de la OCDE sobre información, consulta y participación ciudadana en la elaboración de políticaspúblicas, OCDE, Paris.

Quiroga, M. (2008). "Evaluando la confianza institucional en chile. una mirada desde los resultados LAPOP”, Revista de Ciencia Política, Vol. 28, N³, pp. 161 - 186.

Segovia, C., Haye, A., González, R., Manzi, J., \& Carvacho, H. (2008). Confianza en instituciones políticas en Chile: un modelo de los componentes centrales de juicios de confianza. Revista de ciencia politica (Santiago), 28(2), 39-60.

Paredes, J. (2011), “Ciudadanía, Participación y Democracia Deuda y Déficit en los 20 años de Democracia en Chile", POLIS, Vol. 10, N²8, pp. 473-499. 